\title{
Determinants of Neonatal Mortality in the Health Zone Kenge, DR Congo (2013-2016)
}

\author{
Wivine Nzoko Ngana ${ }^{1,2 *}$, Felix Pindi Piay ${ }^{1}$, Zenga Mukinda ${ }^{1,3}$ and Perpetua Nganda Kitonguna ${ }^{1,4}$ \\ ${ }^{1}$ Assistant Higher Institute of Medical Techniques Mary Queen of Peace Kenge, DRC \\ ${ }^{2}$ Nurse, General Hospital Reference Kenge, Province Kwango DRC \\ ${ }^{3}$ Nurse Supervisor, Health Zone Kenge, Province Kwango DRC \\ ${ }^{4}$ Inspector, Health Zone Kenge, Province Kwango DRC
}

*Corresponding author: Wivine Nzoko Ngana, Assistant Higher Institute of Medical Techniques Mary Queen of Peace Kenge, DRC

\section{ARTICLE INFO}

Received: 陆 May 20, 2019

Published: May 30, 2019

Citation: Wivine Nzoko N, Felix Pindi P, Zenga M, Perpetua Nganda K. Determinants of Neonatal Mortality in the Health Zone Kenge, DR Congo (20132016). Biomed J Sci \& Tech Res 18(3)2019. BJSTR. MS.ID.003156.

Keywords: Child Mortality; Determinant; Neonatality; Normal Distribution; Infant Mortality

\section{ABSTRACT}

Childbirth is a happy event in a family and procreation is the wish of the human society. However, when a Child is born with health problems or dies, it is a moral and social burden for the community. Child mortality is decreasing elsewhere in our global society, there is a lot aim to be done in developing countries, the DRC included. The main goal of this research Was to determine the causes of neonatal mortality at the Kenge area health During the period from 2013 to 2016. The study used an analytical method based was descriptive and correlational design with a sample size of 84757 Amongst Deaths Recorded at the health area Kenge During the Above period. Results show That entre 2013 and 2016 the health area Kenge Recorded year average rate of 19. 2 Deaths of less than 28 days out of 1000 births Estimated Within a confidence interval of 95\% and a Range of 9.5 to 24 Neonatal Deaths. This early neonatal mortality Was Explained by Several factors, purpose Mainly by mothers' irresponsibility and immaturity as well as the distance to health centers, the lack of midwives and premium parity. These Were responsible of the bad status of the baby at delivery gold icts way of delivery and the APGAR persistence after-birth child.

These resulted from Prematurity, dystocia, hypoxia and choke, and infections specific to the perinatal period, qui were found to be Among the Most Significant causes of child death. These determinants of neonatal mortality need to be taken in gravement Addressing the sustainable development goal No. 3 That Promotes maternal child health and wellbeing. 5 to 24 Neonatal Deaths. This early neonatal mortality Was Explained by Several factors, purpose Mainly by mothers' irresponsibility and immaturity as well as the distance to health centers, the lack of midwives and premium parity. These Were responsible of the bad status of the baby at delivery gold icts way of delivery and the APGAR persistence after-birth child. These resulted from Prematurity, dystocia, hypoxia and choke, and infections specific to the perinatal period, qui were found to be Among the Most Significant causes of child death. These determinants of neonatal mortality need to be taken in gravement Addressing the sustainable development goal No. 3 That Promotes maternal child health and wellbeing. 5 to 24 Neonatal Deaths. This early neonatal mortality Was Explained by Several factors, purpose Mainly by mothers' irresponsibility and immaturity as well as the distance to health centers, the lack of midwives and premium parity.

These Were responsible of the bad status of the baby at delivery gold icts way of delivery and the APGAR persistence after-birth child. These resulted from Prematurity, dystocia, hypoxia and choke, and infections specific to the perinatal period, qui were found to be Among the Most Significant causes of child death. These determinants of neonatal mortality need to be taken in gravement Addressing the sustainable development goal No. 3 That Promotes maternal child health and wellbeing. Mainly goal 
by mothers' irresponsibility and immaturity as well as the distance to health centers, the lack of midwives and premium parity. These Were responsible of the bad status of the baby at delivery gold icts way of delivery and the APGAR persistence after-birth child. These resulted from Prematurity, dystocia, hypoxia and choke, and infections specific to the perinatal period, qui were found to be Among the Most Significant causes of child death. These determinants of neonatal mortality need to be taken in gravement Addressing the sustainable development goal No. 3 That Promotes maternal child health and wellbeing. Mainly goal by mothers' irresponsibility and immaturity as well as the distance to health centers, the lack of midwives and premium parity.

These Were responsible of the bad status of the baby at delivery gold icts way of delivery and the APGAR persistence after-birth child. These resulted from Prematurity, dystocia, hypoxia and choke, and infections specific to the perinatal period, qui were found to be Among the Most Significant causes of child death. These determinants of neonatal mortality need to be taken in gravement Addressing the sustainable development goal No. 3 That Promotes maternal child health and wellbeing. dystocia, hypoxia and choke, and infections specific to the perinatal period, qui were found to be Among the Most Significant causes of child death. These determinants of neonatal mortality need to be taken in gravement Addressing the sustainable development goal No. 3 That Promotes maternal child health and wellbeing. dystocia, hypoxia and choke, and infections specific to the perinatal period, qui were found to be Among the Most Significant causes of child death. These determinants of neonatal mortality need to be taken in gravement Addressing the sustainable development goal No. 3 That Promotes maternal child health and wellbeing.

\section{Summary}

The birth of a healthy child in a family is a happy event and procreation is as desired in human society. However, when the child is born with a health problem or died at birth, this causes a moral and social disruption in the community. Although it has been observed that child mortality is declining in most parts of the world, it is still a major problem in developing countries, including the DRC. The main objective of this study was to determine the causes of neonatal mortality in the ZS Kenge in the period from 2013 to 2016. The study used an analytical method to estimate descriptive and correlational of a sample of 84757 enregistrés deaths in ZS Kenge during the above period. The results indicate that between 2013 and 2016, the ZS Kenge recorded a neonatal mortality rate of between 09.5 and 24 deaths less than 28 days 1,000 births with an annual average of 19.2 neonatal deaths. This rate was estimated at a $95 \%$ confidence interval. This early neonatal mortality was explained by several factors but mainly by the irresponsibility and immaturity of the mother and the distance of health centers, the lack of midwives and primiparity. These can be the causes of bad baby's condition at birth or its mode of delivery and the persistence of APGAR after birth. These result among others of prematurity, dystocia, hypoxia and asphyxia, and specific infections in the perinatal period, who were among the most significant causes of death. These determinants of neonatal mortality should be taken seriously in order to achieve the objective of sustainable development No. 3 for the promotion of welfare and maternal health and child.

\section{Introduction}

The birth of a baby is a natural process and an important and joyful social event for the individual family and the wider community. However, the time of birth and the first month is a very risky period for the child (Compaoré). Every year 2 million newborns die within 24 hours of their life, 99\% of these deaths occur in low-income countries. Approximately 4 million births are recorded as neonatal deaths each year worldwide, $3 / 4$ of them occurring in the first week of life with the risk in the first day. WHO (2013) observed that despite a global decline of nearly $50 \%$ of the mortality rate among children under five, which rose from 90 to 48 deaths per 1,000 live births between 1990 and 2012, the neonatal mortality rate only decreased by $36 \%$ from, during the same period, 33 to 21 deaths per 1000 live births. This resulted in children under five years, an increase in the proportion of deaths occurring during the neonatal period, from $37 \%$ in 1990 to $44 \%$ in 2012 when 2.9 million children died in the month after birth, mainly from preventable causes. The neonatal mortality rate is an indicator of the quality of obstetric and neonatal care. It depends on the level of socio-economic development of a country. For SANIFO Hope Foundation (2013), 82\% of newborn deaths are the 58 developing countries classified as high risk, and each year 2 million newborns die within 24 hours of their existence.

In 2015, neonatal deaths accounted for $45 \%$ of total deaths, a proportional increase of $5 \%$ compared to 2000 [1]. According to WHO $[2,3]$. Africa has the neonatal mortality rate estimated as high 45 deaths per 1,000 live births against 5 deaths in developed countries. for Madagascar for example, the demographic and health surveys data (DHS 2003-2004) indicate a neonatal mortality rate of 32 per 1,000 live births. these neonatal deaths account for $55 \%$ of infant mortality (Madagascar, 2004). The main causes of this mortality are prematurity, respiratory distress and neonatal 
infection [4]. Early neonatal mortality in neonatal units in poor countries hospitals may brush against the slaughter in excess of $50 \%$ [5]. And their deficiency of 350,000 midwives worldwide to curb the scourge [6]. The challenge is particularly important in our country, and especially in the health Kenge zone which is exposed to the morbidity and mortality of mother and child. Indeed, maternal, newborn and child is alarming and marked by maternal and child mortality are among the highest in the world, for a ratio of 549 maternal deaths per 100,000 live births, a rates of childhood mortality at 158 to 1,000 , an infant mortality rate 97 to 1000 and a neonatal mortality rate of 42 to 1000 (NIB, 2013) [7]. Despite the efforts, the health of mothers and children remains a concern. This requires effective neonatal mortality reduction programs that take into account the interventions on modifiable risk factors.

Of such interventions will focus on economic and health measures useful for the survival of newborns. Health facilities at the primary level recorded in the majority of cases of pregnant women with limited financial resources, that is to say a low socioeconomic level $[8,9]$. Health facilities at the primary level recorded in the majority of cases of pregnant women with limited financial resources, that is to say a low socioeconomic level. This reality does not save the province Kwango Kenge and specifically the health zone [10]. Our professional experience in Kenge health area, specifically the Catholic Conventionné Reference General Hospital Kenge services maternity and pediatrics showed us that the problems of child deaths including neonatal infections, a birth asphyxia, prematurity, birth defects, a respiratory distress syndrome in jaundice are increasingly alarming Kenge in the health area. What are the real causes of this mortality? And what other risk factors can be targeted by policy? This is what will tackle this study. The general objective of this study is to determine the causes of neonatal mortality in the ZS Kenge. The risk factors are the maternal age, parity, education level, obstructed labor, premature rupture of membranes, sex, underweight, gestational age.

\section{Status Report}

Neonatal mortality is defined as the probability that a newborn will die between birth and 28 days of life. About two-thirds of neonatal deaths occur in the WHO regions of Africa and Southeast Asia. The countries that have the largest number of deaths are mainly found in South Asia, because of the large populations in this region. India alone accounts for nearly a quarter of neonatal deaths [11]. The World Health Organization (WHO) estimates that in 2004 about 3.7 million children died during the first 28 days of life (WHO). This mortality risk experiencing tremendous changes during the neonatal period [12]. Each year 2,000,000 babies die within 24 hours of their existence, $99 \%$ of these deaths occur in low-income countries [6]. In Africa $70 \%$ of the population lives in rural areas and $50 \%$ below the poverty line, while $90 \%$ of qualified personnel is devoted in large urban centers, and only $60 \%$ of women receive prenatal care, half of deliveries take place at home without medical assistance. A midwife formed African supports 500 mothers each year. The Democratic Republic of Congo (DRC) is ranked among the countries with the least progress in child survival.

Its mortality rate of children under five years has remained virtually unchanged for twenty years, from the late 1980s [13,14]. According to WHO [4] 1581000 newborns die every day at birth in the DRC, where only 76 pediatricians are deployed to support a population represented by $20 \%$ of children. Based on data from MICS 2010 and EDS from 2005 to 2006 and from 2013 to 2014, we note that the situation of maternal, newborn and child remains alarming. It is marked by high maternal and child mortality are among the highest in the world, for a ratio of 549 maternal deaths per 100,000 live births, a child mortality rate of 158 per 1,000, an infant mortality rate to 971,000 and a neonatal mortality rate of 42 per $1,000[15,16]$. Despite the efforts, the health of mothers and children remains a concern in the Congo (DRC) as shown by the levels of the indicators collected during the investigation on the state places the health sector in April 1998 [17]. For infants, the risk factors are closely related to the health and future mothers' conditions. The intrauterine growth restriction, which is defined by insufficient fetal growth during pregnancy is a major risk of perinatal death highlights UNICEF [18]. Underweight is associated with malnutrition and poor health of the mother. Neonatal mortality follows the " $2 / 3$ rule" ie $2 / 3$ of infant deaths occur in the first month.

The causes of neonatal mortality as its most important factors to risk are two-fold: the causes and factors of maternal and fetal order, firstly, and secondly, obstetric risk factors and the causes and sociocultural. The fundamental maternal causes of neonatal mortality include congenital uterine malformations, the contracted pelvis, incompatibility maternal fetal rhesus. Risk factors related to the mother include illegitimate pregnancies, unfavorable working conditions and transport, low socioeconomic class and unmonitored pregnancies, age and parity [13]. As for obstetric risk factors, they are for the most part related to pregnancy, including abnormalities in the evolution of pregnancy; premature rupture of the membrane and dystocia; colored amniotic fluid, etc. Finally, socio-cultural factors are behavioral and environmental conditions. For example, neonatal mortality can be attributed to the difficult working conditions and transport, illegitimate pregnancies, which in turn can be explained by parental poverty that forces many women and girls into prostitution to survive (Rachidatou). In developing countries, the main causes of fetal neonatal mortality are infectious diseases including sepsis, pneumonia, tetanus and diarrhea in $36 \%$ of cases.

Premature births and complications attributable to that account for $27 \%$ of deaths, while neonatal asphyxia accounts for $23 \%$ of cases. Of the remaining $14 \%, 7 \%$ of all deaths are associated with a birth defect. From one year to another, prematurity presented in general more than $40 \%$ of neonatal deaths [19]. According to Nguyen Ngoc-study (2006) conducted in 6 countries and those Cissé (2006) conducted Senegal, prematurity and its complications belong to three main causes of neonatal mortality in developing 
countries and occupies the first position, while asphyxiation comes second [8]. On the etiological, conditions usually responsible for respiratory distress of newborn are: perinatal asphyxia by inhalation of amniotic fluid or resorption delay; pulmonary immaturity and perinatal infection; the affections of surgical origins. To these different causes are added acute fetal distress is a condition that threatens the life, health and psychomotor future of the fetus and newborn. The characteristics of this suffering are: Metabolic acidosis, persistent Apgar score less than 3 beyond 5 minutes life; neurological consequences in the immediate neonatal period including seizures, hypotonia, coma, or hypoxic ischemic encephalopathy.

Neonatal infection is a worldwide public health problem and is also among the causes of neonatal mortality. Its incidence is close to $1 \%$ of births in industrialized countries but higher in developing countries. These infections are most often secondary to antenatal contamination by amniotic fluid, colonized from a germ from the vaginal flora. Three nuclei dominate neonatal bacterial infections: B Streptococcus, Listeria and Escherichia coli. The B streptococcus is responsible for 25 to $40 \%$ of infections of the newborn and over half of maternal-fetal infections (Ngoc-Nguyen, 2006). To these different causes befits add birth defects, the most common being the polymalformations, cleft palate (cleft lip and slots), and cleft lip (cleft lip) followed by congenital heart disease, malformations in small proportions but as serious digestive malformations, hydrocephalus and anencephaly. Originally hypoxia and anemia, placenta previa is also cited among the causes of fetal neonatal deaths $[19,20]$.

\section{Materials and Methods}

\section{Description of the Study Environment}

Our study is among the Rural Health Zone (Kenge Kenge ZS). She is one of 14 health zones of the Provincial Health Division Kwango (DPS-Kwango). The health zone covers an area of 5559 $\mathrm{km} 2$ on the $89,458 \mathrm{~km}^{2}$ that account Province Kwango. The ZS Kenge has a population of 300,207 inhabitants with a density of 54 inhabitants / $\mathrm{km}^{2}$ divided into 28 health areas of 28 health centers each, while the provincial density was 28 inhabitants $/ \mathrm{km}^{2}$ in 2014 [21]. The Kenge health zone was delineated in October 1984, in the former province of Bandundu, in the first the first regional conference on the promotion of care. The ZS Kenge is currently found in the Province of Kwango and specifically in the town of Kenge. It is located $275 \mathrm{~km}$ from the city of Kinshasa, on National Highway No. 1 (Kinshasa-Kikwit). It is bounded to the north by the Kikongo health zone and Bonga-Yassa, south by the Kimbao health zone and Moanza, to the west by the Boko health zone, to the east by the Health Zone of Masimanimba [22].

Province Kwango along with wide a tropical climate zone with two rainy seasons (September- January, and March-May) and two dry seasons (May to September; January-March). This partly explains the presence of the herbo-boiseuse savannah. The City of Kenge is entirely on plateaus intersected by valleys, and sometimes the hills between Wamba rivers to the west and east Bakali (Figure
1). The soil is sandy type Kenge Kalahari Karoo. The vegetation consists mainly of grassland, woodland and gallery forests found along streams [10] (Figure 1). Populationthe ZS Kenge is $80 \%$ rural and agricultural activities are the main source of income. The trading companies also provide employment in the trading areas, small and medium enterprise, mototaxis well as education, health and public administration. This population is essentially from the Yaka ethnic group but can be cosmopolitan in urban areas. It includes the populations of ethnic groups and tribes Yaka Pelende, Mbala, Suku, Hungani, Kongo, Ngala, Swahili and phones. The Pelende tribe is the majority in the ZS [23].

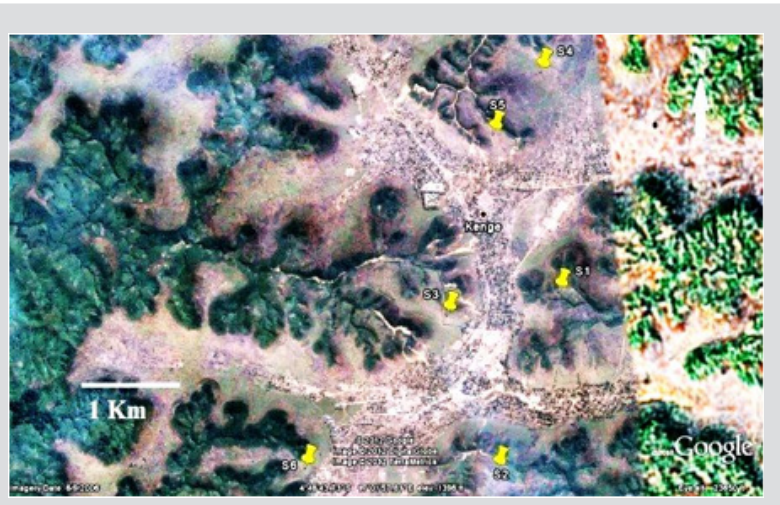

Figure 1: Mapping the hills and valleys of the city of Kenge (Google, 2018).

\section{Sampling Method and Techniques Data Collection}

Methods and Data Collection Techniques: This study is to identify the causes of neonatal mortality in the ZS Kenge in the period from 2013 to 2016. The study used an analytical method on a non-random sample of 84 comprehensive neonatal deaths of 757 registered in the ZS Kenge during the above period. The choice of non-probability sampling method but comprehensive was dictated by the occurrence random cases of neonatal deaths. As for the data collection techniques, the study is based on data from a survey sanitary Quantitative cross descriptive and analytical estimates. Data collection instruments were the registry, partographs mothers who gave birth to dead babies and newborns sheets died before the $7^{\text {th }}$ day of their births.

Selection Criteria: Before including a child in the study sample, the researchers considered two following criteria:

(i) Newborns died in the maternity; and

(ii) Newborns died on the $7^{\text {th }}$ day before the $7^{\text {th }}$ day of birth in the service of pediatrics and health centers.

\section{Exclusion Criteria}

Were excluded from the sample this study, all new life born, and newborns died after 7 days of their births.

\section{Data Analysis Techniques}

The study made use of descriptive and inferential statistics to analyze the from data partographs and cards containing the ad hoc information. Descriptive statistics allowed detect the prevalence of 
neonatal mortality through the calculation of the frequency, mean, mode, median, standard deviation, and the Z-score. The calculation of the frequencies has been to describe the sample workforce by age and sex based on Equation 1:

$$
f=\frac{F 0}{F A} * 100
$$

[Equation 1]

Or,

Relative frequency $\mathrm{f}=$

FO = Observed frequency

$\mathrm{FA}=$ expected frequency

Inferential statistics was essentially based on the multivariate analysis based on the multiple linear regression. The multiple linear regression model following (Equation 2) was used to evaluate the factors determining neonatal mortality in the health aerated Kenge:

$$
Y i=(b 0+b 1 x 1+b 2 \times 2+\ldots+b n x n)+\varepsilon i
$$

(Equation 2)

Or

Yi = number of deaths within 7 days

$\mathrm{xi}=$ the explanatory variable $\mathrm{Yi}$

$\mathrm{bi}=$ the parameter or coefficient for estimating the predictor $\mathrm{xi}$

$\varepsilon i=$ the random variable or term error model

Given the quantitative nature of the dependent variable, the method of least squares estimation of Pearson was used. The quality of the model parameters was assessed through the test $t$ of Students. The relevance of the model has been validated with $5 \%$ significance level by the coefficients of determination R2 and R2 Adjusted and statistical $\mathrm{F}$ test of Fisher and Snedecor, which is the ratio of the analysis of variance of regression ( ANOVA).The statistics $F$ was tested at the $5 \%$ significance level $(p=0.05)$, using computer software SPSS 12.0 and MS Excel 2010.The following assumptions have been-used for detect normality explained variations or of the sum of squares regression neonatal mortality [Var (R2)] compared to those of the sum of residual squares or unexplained variations of neonatal mortality [Var (1-R2)] according to: a) H0: $\operatorname{Var}(\mathrm{R} 2) \operatorname{Var}=(1-\mathrm{R} 2)$ The prediction model is not normally distributed that is to say the regression coefficients are not normally significant, because they are all due to chance that the residual variations.

b) H1: $\operatorname{Var}(\mathrm{R} 2) \neq \operatorname{Var}(1-\mathrm{R} 2)$ The prediction model is normally distributed is to say that the regression coefficients are normally significant, as they are not due to chance as the residual variations.

After this test, the neonatal mortality was declared normally distributed if the null hypothesis was rejected 95\% confidence level (Or a threshold meaning lower than or equal to $5 \%$ ). this analysis gave us more information about the quality of the factors used in the model and significantly explain the variability neonatal mortality in the health aerated Kenge.

\section{Analysis Results}

This study has identified both the prevalence of neonatal mortality and its root causes in Kenge health zone during the period from 2013 to 2016.

\section{Characteristics of Newborns and their Mothers}

Table 1 shows the characteristics of mothers and babies surveyed in Kenge Health Zone. It appears from this table that all pregnant women are recorded as being married yet, this does not reflect the reality of their marital status. Furthermore, most of the mothers in the age thirty (83\%), probably for fear of the very few rural women menopauses have completed secondary or higher education (37\%) and most have large families ( $>4$ children). Regarding sanitary and socioeconomic characteristics of the surveyed mothers and babies, Table 2 shows that most deliveries among primiparous experienced complications (41.7\%), and this at cause of asphyxia, neonatal infection and prematurity (Table 1). Many cases complications are referred to the hospital because of distance remote from the health center (46.4\%). Unfortunately, most of the traditional midwives who dropped their train service to police harassment suffered during and after childbirth, only $15.5 \%$ of births were attended by midwives (Table 2 ).

\begin{tabular}{|c|c|c|c|c|}
\hline Variable & Value & NOT & $\%$ & Observation \\
\hline \multirow{2}{*}{ Civil status } & Single & 0 & 0.0 & \multirow{2}{*}{ Most of married women of alleged } \\
\hline & Married & 84 & 100.0 & \\
\hline \multirow{3}{*}{ Age } & Less than 16 & 14 & 16.7 & \multirow{3}{*}{ Most of mothers are in the age thirty menopause by fear } \\
\hline & 16- 35 & 43 & 51.2 & \\
\hline & More Than 35 & 27 & 32.1 & \\
\hline \multirow{3}{*}{ Level of education } & Primary & 53 & 63.1 & \multirow{3}{*}{ Very few women have completed secondary or higher } \\
\hline & Secondary & 29 & 34.5 & \\
\hline & Superior & 2 & 2.4 & \\
\hline Parity & Less than 2 & 20 & 23.8 & $\begin{array}{c}\text { Many mothers have given birth several times. Stillbirths are } \\
\text { sometimes repeated in families }\end{array}$ \\
\hline
\end{tabular}

Table 1: Demographic Statistics describing the children's mothers. 


\begin{tabular}{|c|c|c|c|c|}
\hline & $2-5$ & 38 & 45.2 & \\
\hline & More Than 5 & 26 & 31 & \\
\hline \multirow{3}{*}{$\begin{array}{l}\text { Number of chil- } \\
\text { dren }\end{array}$} & Less than 2 & 11 & 13 & \multirow{3}{*}{ Most of families are numerous. } \\
\hline & $2-5$ & 40 & 47.6 & \\
\hline & More Than 5 & 33 & 39.2 & \\
\hline
\end{tabular}

Source: Authors (2017).

Table 2: Health and socio-economic statistics of the Health Zone Kenge.

\begin{tabular}{|c|c|c|c|c|}
\hline Variable & Value & NOT & $\%$ & Observation \\
\hline \multirow[t]{2}{*}{ Complications in childbirth } & Yes & 35 & 41.7 & \multirow[t]{2}{*}{ Most complications were recorded among primiparous } \\
\hline & No & 49 & 58.3 & \\
\hline \multirow[b]{2}{*}{ Death of a baby less than 7 days } & Yes & 23 & 27.4 & \multirow[b]{2}{*}{$\begin{array}{l}\text { Most deaths are due to asphyxia, neonatal infection and } \\
\text { prematurity }\end{array}$} \\
\hline & No & 61 & 72.6 & \\
\hline \multirow{2}{*}{ Presence of midwives } & Yes & 13 & 15.5 & \multirow{2}{*}{$\begin{array}{l}\text { Most traditional midwives left the service because of police } \\
\text { harassment }\end{array}$} \\
\hline & No & 71 & 84.5 & \\
\hline \multirow{2}{*}{ Agricultural Work } & Yes & 79 & 94 & \multirow{2}{*}{ Most village women are agriculture } \\
\hline & No & 4 & 6 & \\
\hline \multirow{2}{*}{ Significant non-farm income } & Yes & 49 & 58.3 & \multirow{2}{*}{ Most urban women are petty trade } \\
\hline & No & 35 & 41.7 & \\
\hline \multirow{2}{*}{ Distance nearest health center } & Yes & 45 & 53.6 & \multirow{2}{*}{ Case of complications often referred to hospital } \\
\hline & No & 39 & 46.4 & \\
\hline
\end{tabular}

Source: Authors (2017).

Primiparity really was a major factor in determining the baby's condition at birth. Many mothers have given birth several times before having a live birth, stillbirth repeating sometimes in families. Thus, parity has turned around 5 deliveries (45.2\%). In most cases, there were complicated deliveries and deaths due to asphyxia, neonatal infection and prematurity among first-time (41.7\%). These cases complications were often referred to the hospital, and most salient by neonatal deaths. Finally, agriculture remains an important activity among pregnant women. The majority of pregnant women were village (Figure 2) and had made agriculture their career (94\%). Only a few of them enjoyed, like the urban women, nonfarm income, especially to do petty trade (58.3\%) (Figure 2). Figure 2 shows that most mothers residing in the municipality of Kenge and surrounding villages. Of these, 32.1\% lived in Kikwit Camp, $22.6 \%$ at Camp SAS, $14.3 \%$ in EPOM Camp, and the rest came from other districts and surrounding villages Kenge (31\%).

\section{Determining Factors for Neonatal Mortality}

Even the number of live births is pretty normal in this area, the rather worrying trend of stillbirth is a major concern of nongovernmental and political organizations responsible for providing reproductive health. Thus, the least squares method used in this study allowed us to predict, with high accuracy, the most significant determinants of neonatal mortality in the Health Area of Kenge. Tables 3 \& 4 give us an overall view of these determinants. From Table 3, between 2013 and 2016, 79 and 199 babies died at birth in 8722 live births with an average of 167 neonatal deaths estimated at a 95\% confidence interval. This amounts to a neonatal mortality rate of between 09.5 and $24 \%$ o with an average rate of 19.2\%oexplained by various causes. However, the sample used in this study does not allow us to confirm that the marital status, type of work (agricultural or not) and the number of children of the mother, mode of delivery, the presence of midwives, the patented cord and parity were also significant in determining neonatal mortality in the health Area of Kenge.

Other factors listed above have presented regression parameters with coefficients (B) significant at 95 or $99 \%$ confidence level. These include: a fairly young maternal age at delivery $(b=-2.32$, $\mathrm{t}=-75.99 ; \operatorname{sig}=0.00$.$) , The instruction of the mother (\mathrm{b}=1.59 ; \mathrm{t}$ $=28.11$; Sig = 0.00), underweight at birth $(\mathrm{b}=-1.43, \mathrm{t}=-59.51$; sig $=0.00)$, an obstructed childbirth term $(b=1.81, t=89.53$; sig $=-0.00)$, a sufficient distance from the health center $(b=1.93 . t=$ 91.83; sig = 0.00), low non-farm incomes $(b=-1.12$, $t=-48.65$; sig $=0.00)$, recurrent complaints front and delivery $(b=8.70 ; t=3.91$; $\operatorname{sig}=0.00)$; recurrence of prenatal infections $(b=0.40 ; t=2.01$; sig $=0.05$ ), the presence of specific infections during périnatathe $(b=3.25 ; t=4.05 ; \operatorname{sig}=0.03$ ) (Table $3 \& 4$ ). Table 4 indicates that neonatal mortality is due to Apgar index lower at birth $(b=0.20 ; t=$ 2.07; Sig = 0.04); a much more colorful appearance of the amniotic fluid ( $\mathrm{b}=8.68 ; \mathrm{t}=4.78$; $\mathrm{sig}=0.00$.); the presence of hypoxia and asphyxia during labor $(\mathrm{b}=-2.18, \mathrm{t}=-46.58$; sig $=0.00)$; the 
presence of perinatal and neonatal jaundice $(b=2.82 ; t=13.44 ; 1.98, t=87.92 ; \operatorname{sig}=0.00)$; and the presence of congenital defects in $\operatorname{sig}=0.00)$; respiratory distress syndrome during childbirth $(b=$ newborns $(b=1.79 ; t=23.82 ;$. sig $=0.00)$.

Table 3: Determinants of death within 7 days related to the status of the mother in Kenge.

\begin{tabular}{|c|c|c|c|c|c|c|c|}
\hline \multirow{2}{*}{ Variables } & Non-Standardized Coefficients & Standardized Coefficients & \multirow{2}{*}{ t } & \multirow{2}{*}{ Sig. } & \multicolumn{2}{|c|}{ Confidence Interval B (95\%) } \\
\cline { 2 - 7 } & B 3 & Error Type & Beta & & Lower bound & Upper bound \\
\hline (Constant) & $185.43^{*}$ & 91.98 & & 2.04 & 0.04 & 79.03 & 199.11 \\
\hline Civil status & --- & -- & -- & -- & --- & -- & -- \\
\hline Age of mother & -2.3 & 0.03 & -1.00 & -75.99 & 0.00 & 19.25 & 44.5 \\
\hline Maternal education & $1.59^{* *}$ & -057 & 0.98 & 28.11 & 0.00 & -0.12 & 0.54 \\
\hline Number of children & -23.86 & 35.33 & -0.12 & -0.68 & 0.50 & -94.94 & 7.22 \\
\hline Mode of delivery & -0.67 & 1.56 & -0.19 & -0.43 & 0.69 & -7.22 & 28.18 \\
\hline Delivery term & $1.81^{* *}$ & 0.02 & 1.00 & 89.53 & 00 & -7.96 & 2.91 \\
\hline Prenatal Infections & $0.40^{*}$ & 0.20 & 0.27 & 2.01 & 0.05 & -4.35 & 7.24 \\
\hline Perinatal Infections & $3.25^{*}$ & 0.80 & 0.92 & 4.05 & 0.03 & -6.84 & 8.08 \\
\hline Parity & -0.61 & 0.70 & -0.53 & -0.88 & 0.47 & -17.86 & 14.79 \\
\hline Complaints childbirth & $8.70^{* *}$ & 7.34 & 053 & 3.91 & 0.00 & -15.01 & 31.30 \\
\hline Presence midwives & 1.22 & 1.03 & 1.00 & 00,00 & 99.99 & -2.32 & 1.74 \\
\hline Distance health center & $1.93^{* *}$ & 0.02 & 1.00 & 91.83 & 0.00 & -0.04 & 0.01 \\
\hline Agricultural Work & 3.63 & 3.70 & 3.33 & 0.98 & 32.93 & -0.19 & 1.81 \\
\hline Off-farm income & $-1.12^{* *}$ & 0.02 & -1.00 & -48.65 & 0.00 & -10.05 & 0.07 \\
\hline
\end{tabular}

source: Authors (2017)

Notes:

1) Variable Dépendante: Number of deaths before birth or before reaching 7 days of age

2) Model type: Multiple Linear

3) The parameter value in specific units

*Parameter statistically significant at 95\% confidence interval

**Parameter statistically significant $99 \%$ confidence interval

Table 4: Determinants of death within 7 days related to the baby's condition in Kenge.

\begin{tabular}{|c|c|c|c|c|c|c|c|}
\hline \multirow{2}{*}{ Variables } & \multicolumn{2}{|c|}{ Non-Standardized Coefficients } & \multirow{2}{*}{$\begin{array}{c}\text { Standardized Coeffi- } \\
\text { cients } \\
\text { Beta } \\
\end{array}$} & \multirow{2}{*}{$\mathbf{t}$} & \multirow{2}{*}{ Sig. } & \multicolumn{2}{|c|}{ Confidence Interval B (95\%) } \\
\hline & B 3 & Fault Type & & & & Lower bound & Upper bound \\
\hline (Constant) & $185.43^{*}$ & 91.98 & & 2.04 & 0.04 & 79.03 & 199.11 \\
\hline Birth Weight & $-1.43^{* *}$ & 0.02 & -1.00 & -59.51 & 0.00 & -0.01 & 0.01 \\
\hline Brevity cord & 0.10 & 0.29 & 0.32 & 0.33 & 0.80 & -8.37 & 25,14 \\
\hline APGAR at birth & $0.20^{*}$ & 0.10 & 0.30 & 2.07 & 0.04 & 0.40 & 1.00 \\
\hline Aspect of amniotic fluid & $8.68^{* *}$ & 7.12 & 0.61 & 4.78 & 0.00 & -14.37 & 29.45 \\
\hline Hypoxia and asphyxia & $-2.18^{* *}$ & 0.05 & -1.00 & -46.58 & 0.00 & -5.44 & 1.78 \\
\hline Jaundice peri / neonatal & $2.82^{* *}$ & 0.21 & 0.98 & 13.44 & 0.00 & -4.43 & 7.22 \\
\hline Respiratory distress syndrome & $1.98^{* *}$ & 0.02 & 1.00 & 87.92 & 0.00 & -4.23 & 9.45 \\
\hline Birth defects & $1.79^{* *}$ & 0.08 & 0.99 & 23.82 & 0.00 & -0.03 & 4.71 \\
\hline
\end{tabular}

source: Authors (2017)

Notes:

Variable Dépendante: Number of deaths before birth or before reaching 7 days of age

Model type: Multiple Linear

The parameter value in specific units

*Parameter statistically significant at $95 \%$ confidence interval

**Parameter statistically significant $99 \%$ confidence interval 


\section{Performance Evaluation of the Regression Model}

Table 5 shows that the neonatal mortality prediction model had proved statistically relevant. It recorded a high rate of adjustment represented by an adjusted coefficient of determination (adjusted
R2) greater than 0.50 and a statistically significant $\mathrm{F}$ value $99 \%$ confidence interval. This means that factors related to neonatal mortality were normally distributed and therefore could not be coincidence.

Table 5: Performance prediction of neonatal mortality in the model ZS Kenge.

\begin{tabular}{|c|c|c|c|c|c|}
\hline \multicolumn{7}{|c|}{ Summary Modèlea b } \\
\hline $\mathbf{R}$ & R2 & \multicolumn{2}{|c|}{ Adjusted R2 } & Standard Error of Estimate & Durbin-Watson (DW) \\
\hline 0.764 & 0.584 & \multicolumn{2}{|c|}{0.573} & 3887.99 & 1,878 \\
\hline \multicolumn{7}{|c|}{ ANOVAb } & F & \multirow{2}{*}{ Sig. } \\
\hline & Sum Square & dOF & $\begin{array}{c}\text { Means } \\
\text { Square }\end{array}$ & 43,90 & \\
\hline Regression & 28773.10 & 18 & 1598.51 & & \\
\hline Residues & 1420.05 & 39 & 36.41 & & \\
\hline Total & 30193.15 & 57 & & & \\
\end{tabular}

Source : Authors (2017).

Notes:

at. The equation was estimated with a constant term

b. The independent variables are presented in Tables 3 and 4 above

\section{Discussion on the Determinants of Neonatal Mortality} in Kenge

This study of neonatal mortality in the Health Zone Kenge revealed that between 2013 and 2016 the health area recorded an average of 167 neonatal deaths in 8722 live births on a confidence interval of $95 \%$ with a rank of 79-199 deaths under 28 days. This amounts to an average neonatal mortality rate of $19.2 \%$ o varying between 9.5 and 24.0\%o. These rates are similar to observations made in Sub-Saharan Africa andin Morocco by Compaore (2009). Indeed, despite the efforts of the Ministry of Public Health on the reproductive health in this country, neonatal mortality has remained high and has even seen its rate increase of 20 per 1,000 live births to $27 \%$ o between 1997 and 2004 (Table 5). For their part, Amon-Tanoh-Dick [24] posted a death rate of 28.2\%oin 2006 the neonatology department of the University Hospital of Yopougon in Ivory Coast. These early neonatal mortality rates are not significantly different from those found at Cameroon, Algeria and Vietnam [25]. If harnessing the case of Algeria, and Moulkhaloua Belkheir [26] have evaluated the neonatal mortality rate to $26.1 \%$ o in 2012, while that of France was fixed at 03\%oin 2010, according to statistics from the National Statistics Office (NSO).

In comparing Vietnam, Phan (2000) found a rate of 24.4 per 1,000 live births in the main maternity Hanoi in 1991-1995. That is to say, qhen though the number of live births is considered to be quite normal in the Health Area Kenge, the trend of deaths at birth is quite alarming and should be a major concern of non-governmental and political organizations responsible for ensuring the health reproduction. Indeed, our study found that the irresponsibility and immaturity of the mother were found among the leading causes of neonatal mortality in the Health Area Kenge. They were derived from the mother's age, marital status, education, type of work and income, number of children, etc. Moreover, poor baby's conditionat childbirth or its mode of delivery results from prematurity after childbirth, dystocia, hypoxia and asphyxia, low birth weight, complaints childbirth, distress syndrome breathing, shortness of umbilical cord, the amniotic fluid aspect, prenatal infections and other infections specific atthe perinatal period, and distance from health centers, the presence of midwives, gender, the presence of the APGAR at birth, presence of jaundice peri / neonatal and many other anomalies birth.

These same determinants summers found Nagaloka (2013), Chelo [27], Bezzaoucha [5], Berthin [28] and UNICEF [19] in their respective studies. However, the least squares method used in this study allowed us to predict, with high accuracy, the most significant determinants of neonatal mortality in the Health Area of Kenge. It does not allow us to confirm that the marital status, type of work (agricultural or not) and the number of children of the mother, mode of delivery, the presence of midwives, the patented umbilical cord and parity were also significant in determining neonatal mortality in the health Area of Kenge. Other factors listed above will experience significant regression parameters to 95 or 99\% confidence level including a fairly young age of the mother at delivery, maternal education, underweight at birth a delivery term obstructed A sufficient distance from the health center, weak non-farm income, recurring complaints before and childbirth; the recurrence of prenatal infections, the presence of specific infections in the perinatal period, an index lower APGAR at birth; a more colorful appearance of amniotic fluid; the presence of hypoxia and asphyxia during labor; the presence of perinatal and neonatal jaundice; respiratory distress syndrome during childbirth; and the presence of birth defects in newborns. 
Finally, all pregnant women are recorded as being married yet, this does not reflect the reality of their marital status. Furthermore, most of the mothers in the age thirty (83\%), probably for fear of menopause. Very few rural women have completed secondary or higher education (37\%) and most have large families ( $>4$ children). Many of these mothers have given birth several times before having a live birth; stillbirths sometimes repeated in families. Thus, parity rotates mainly around 5 deliveries (45.2\%). In most cases, there were complicated deliveries and deaths due to asphyxia, neonatal infection and prematurity among first-time (41.7\%). These case complications are often referred to hospital but most soldent in neonatal deaths. However, the Royal College of Obstetricians and Gynecologists [29] observed that the rates of maternal and neonatal mortality are also high due in part to low utilization of maternity services. The latter is dependent on poor reception and overbearing attitude of care providers, medical practices conducted routinely, not based on scientific evidence that can be dangerous and / or ineffective. Kwango in general, and Kenge Health Zone in particular, lags behind in almost all areas are among the most affected by neonatal mortality provinces.

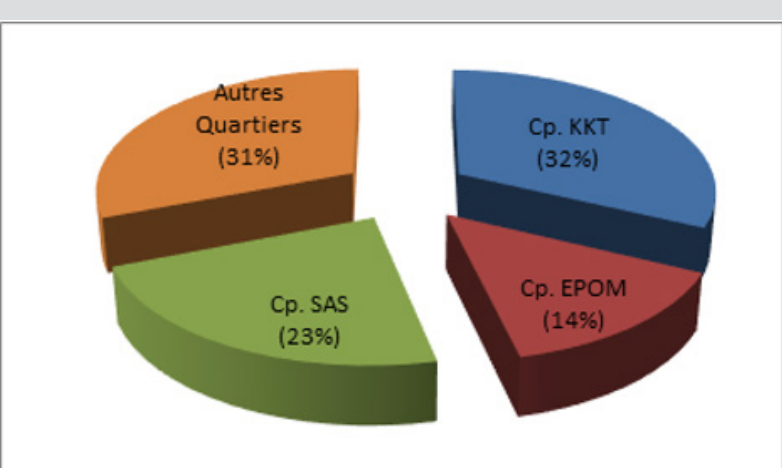

Figure 2: Distribution of women surveyed by residential areas of Kenge.

In 1984, only 13 doctors had charge of the entire district, one doctor for 65,000 inhabitants on an area covering about 97 $000 \mathrm{~km} 2$. The territories of Kasongo Lunda and Kenge proved particularly poor. Depending on whether one takes into account the official population estimates or projections for the year 2006 on the basis of electoral lists, that represents barely one doctor for more than 186000 inhabitants or doctor for 114,000 people instead of 5000 recommended persons [23]. Serengbe (2000) had them found that the main causes of the MNN in developing countries included infectious diseases in $36 \%$ of cases (infections related to sepsis, pneumonia, tetanus and diarrhea) premature birth and complications attributable to that (27\%), birth asphyxia (23\%) and other complications representing 14\%, of which $7 \%$ of deaths due to congenital abnormalities (Figure 2). According to the International Classification of Diseases (ICD), almost half of the causes of MNN in developed countries is reflected in the affections of the perinatal period. The second largest category of causes of neonatal deaths is represented by birth defects that constitute $27.5 \%$ of deaths. However, the causes of maternal and obstetric represent a relatively small share of $2.4 \%$ of deaths due to maternal factors and $4.3 \%$ to complications of labor and delivery. Half of birth defects regarding abnormalities of the heart and circulatory system [30]; (Vendittelli and Lachcard, 2002) (Figure 3).

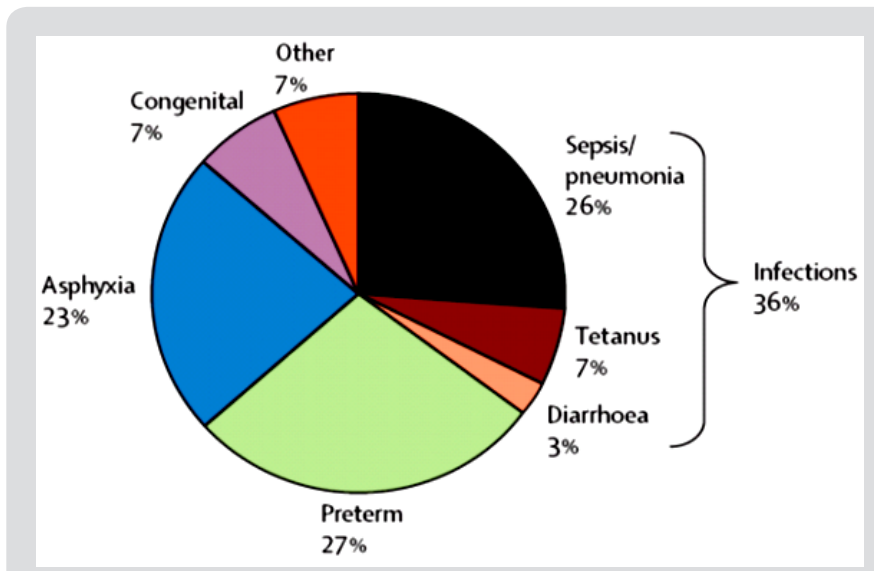

Figure 3: Main causes of neonatal mortality in the developing countries (Serengbe et al. 2000).

However, deaths due to prematurity and birth asphyxia remain important during the early neonatal period; and 60 to $80 \%$ of deaths occur among children with very low weight. Low birth weight is considered a risk factor rather than a direct cause of death, since it is often related to the mother's health (Serengbe et al., 2000). Therefore, good care of mother and newborn would be the basis of the decline in death rates due to infection or respiratory distress. For example, tetanus, who was among the main causes of neonatal deaths has decreased in importance with the intensification of vaccination [31]. Finally, the quality of care improves with midwifery training, which must be increasingly able to anticipate certain complications even before the child's birth [28]. Indeed, prenatal care and deliveries are conducted by nurses trained for this purpose. There is no doctor to support pregnant women outside the pediatrician who provides neonatal consultations twice a week [32]. Clinical evaluation of newborns and their orientation lies with the staff most of whom (80\%) did not receive training in obstetric and neonatal essential and emergency by the World Health Organization (Monebenimp 2012). With the improvement of the training of midwives, the quality of care must necessarily follow [31].

\section{Conclusion and Recommendation}

\section{Conclusion}

The descriptive and analytical design used in this study to determine the normality of neonatal mortality in Kenge health zone to help reduce early mortality of our children. It is proposed to answer the question of whether neonatal mortality was normal or abnormal in that area. The target population consisted of infant's dead children from birth until the 7th day of birth between 2013 and 2016 in Kenge health zone. The total population was 757 cases and the sample of 84 cases. The results of the analysis indicate between 2013 and 2016 the Health Zone Kenge recorded an average of 167 neonatal deaths in 8,722 live births over a 95\% confidence interval 
with a rank from 79 to 199 deaths under 28 days. This amounts to an average neonatal mortality rate of $19.2 \%$ o varying between 9.5 and $24.0 \%$ o. Thus, neonatal mortality stood around 19 deaths in less than a month in 1000 births. This rate approximates the observations made in Sub-Saharan Africa whose are variations are explained by various causes [33-37].

The following risk factors were identified: obstructed labor, premature rupture of membranes, parity, number of children, age of the mother, marital status, education level, type of work and income, underweight, gestational age and pathologies during pregnancy. These factors were directly correlated with the irresponsibility and immaturity of the mother. Moreover, poor baby's condition at birth or its mode of delivery were the result of prematurity, dystocia, hypoxia and asphyxia, low birth weight, complaints to delivery, respiratory distress syndrome, the shortness of the umbilical cord, the amniotic fluid appearance, prenatal infections and other specific infections at the perinatal period, and distance from health centers, the presence of midwives, gender, presence of APGAR at birth, presence of jaundice peri / neonatal and as other congenital anomalies.

\section{Recommendations}

Neonatal death is a problem that does not only concern the health staff but also parents and administrative authorities. Among other things, we recommend politico-administrative and health authorities to provide hospitals and health centers with adequate means to intervene in time on women in labor and delivery and or newborns with serious risk of death. Medical personnel, we recommend observing the rules of asepsis during delivery and standards of the refocused prenatal visit. They have to ensure good care for sick newborns and premature. Pregnant women and new mothers to reduce their exposure to promiscuity and to voluntarily accept public action to promptly adhere to the instructions of the health authorities, including the start time of the EIC, compliance with appointments, the personal and food hygiene, etc. The Ministry of Health will instruct the provincial health authorities to ensure the risk factors for neonatal mortality in the most remote health facilities in each province. These include obstructed labor, premature rupture of membranes, maternal age, gender, educational level, underweight, gestational age and the pathologies during pregnancy. This is how they can facilitate the implementation of the national policy of waiting $0 \%$ of neonatal mortality. It goes without saying that such action can only succeed if health areas are strongly committed to support health structures in terms of staff training, and monitoring and evaluation of the practical implementation of the national policy on fight against infant mortality in the DRC [38].

\section{Suggestions for Future Research}

A single study cannot help determining the real causes and factors to be targeted by policies to prevent neonatal deaths in the ZS Kenge. Replicas of such a study in other health facilities will identify several relevant causes of the normality of neonatal mortality in the health area. They may also validate the suspected risk factors such as maternal age, parity, education level, obstructed labor, premature rupture of membranes, sex, underweight, gestational age.

\section{Author Contributions}

This research is part of the license memory the Assistant Wivine Nzoko Ngana, memory realized Division of Nursing ISTM-MRP Kenge, Democratic Republic of Congo (DRC), during the academic year 2016 -2017, under the direction of Prof. John Inipavudu Baelani and Head of Works Dr. Chiara Castelani. The authors much appreciate their contributions and those of the other co-authors in finalizing this paper.

\section{References}

1. UNICEF (2016) 70 years for each child - The situation of children in the world. Secretariat of UNICEF, Geneva, Switzerland.

2. WHO (2005a) Opportunities for every mother and every child. Health Report in the world. WHO Secretariat, Geneva, Switzerland.

3. WHO (2005b) The survival of the newborn. WHO Secretariat, Geneva, Switzerland.

4. WHO (2010) Bulletin of the WHO health. WHO Secretariat, Geneva, Switzerland.

5. Bezzaoucha A, Kebboul A, A Aliche (2008) The evolution of neonatal mortality at the University Hospital of Blida (Algeria), from 1999 to 2006. Bulletin de la Société de pathologie exotique 103(1): 29-36.

6. Sanofi Espoir Fundation Award for Midwives (2013) Fight against infant mortality in developing countries. London, United Kingdom.

7. (2012) DRC Democratic Republic of Congo. Standards of health zone on integrated interventions of health of the mother, newborn and child in the Democratic Republic of Congo. Secretariat General for Health, Kinshasa, DRC.

8. (2002) Geneviève, Proposal Paper for the $21^{\text {st }}$ century - Reproductive health and public policy. Research Unit in Reproductive Health and Society, Institute of Research for Development (IRD) in Montpellier, France.

9. Balaka B, Agbere AD, And Kpemissi E (1998) The evolution of early neonatal mortality in 10 years 1981-1982, 1991-1992, at the University Hospital of Lome. What health policy for tomorrow? Journal of Medicine in Black Africa 30.

10. Luwesi CN (2018) How the changing environmental trends lead to chronic undernutrition and foodshortage in Kenge Municipality, DRC. Proposal Submitted to The Friedman School of Nutrition at Tufts University, USA and the London School of Hygiene and Tropical Medicine, UK.

11. WHO (2007) Neonatal mortality in the Region Eastern Mediterranean determinants and strategies for achieving the fourth Millennium Development goal no 4. World Health Organization.

12. (2008) UNICEF. The situation of children in the world 2009 - Maternal health. Secretariat of UNICEF, Geneva, Switzerland.

13. Nzoko NW (2017) Problems of neonatal mortality in Kenge health zone (2016-2017). License Memory Education and Nursing Administration. Division of Nursing, ISTM-MRP Kenge Kenge, DRC.

14. (2014) Save the Children. The situation of the World's Mothers 2014 Saving mothers and children in humanitarian crises. London, United Kingdom.

15. (2015) DRC Democratic Republic of Congo. Second Demographic and Health Survey (DHS-RDC II 2013-2014). MINIPLAN and MOH, Kinshasa, DRC. 
16. (2007) DRC Democratic Republic of Congo. Demographic and Health Survey (DHS-RDC I 2005-2006). MINIPLAN and MOH, Kinshasa, DRC.

17. (2001) DRC Democratic Republic of Congo. Blueprint for Health Development 2000-2009. Secretariat General for Health, Kinshasa, DRC.

18. (2013) UNICEF, WHO, World Bank, United Nations. 2013 Report: Levels and Trends in Child Mortality. Secretariat of UNICEF, Geneva, Switzerland.

19. UNICEF (2003) Opportunities for every newborn in Africa. Secretariat of UNICEF, Geneva, Switzerland.

20. Gentilini, Duflo B (1992) Tropical Medicine. Ed. Flammarion MedecineSciences, Paris, France.

21. (2018) DPS, Provincial Directorate of Health Kwango. Health Screenings 2018. DPS -Kwango, Kenge, DRC.

22. (2018) City of Kenge Kenge, administrative Census 2017: Mayor of the City of Kenge, Province Kwango DRC.

23. Omasombo J, Zenga J, William L, M'pene Z, Zana, et al. (2012) Kwango, the Land of Bana Lunda. Ed. The Scream, Tervuren, Belgium.

24. Amon Tanoh Dick F, JP Yenan, Lasme Guillao E Akafou AE, N'Guessan AR, et al. (2009) neonatal mortality risk factors in a tertiary hospital in Abidjan (Ivory Coast). African Journal of Anesthésie- Resuscitation and Emergency Medicine 30.

25. (2011) CAMR. Cameroon, Demographic and health surveys in Cameroon. National Statistics Institute, Yaounde, Cameroon.

26. Moulkhaloua Belkheir NS (2016) Neonatal mortality. Abubakr Belkaïd University, Tlemcen, Algeria.

27. Chelo David, Francisca Monebenimp (2008) Neonatal mortality and its determinants in a tertiary maternity in Yaoundé. National Statistics Institute, Yaounde, Cameroon.

\section{ISSN: 2574-1241}

DOI: 10.26717/BJSTR.2019.18.003156

Wivine Nzoko Ngana. Biomed J Sci \& Tech Res

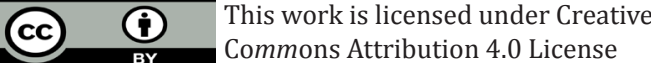

Submission Link: https://biomedres.us/submit-manuscript.php
28. Berthin A (2004) Factors of early neonatal mortality in obstetrics gynecology CHU Befelatanana. of final dissertation. National Institute of Public and Community Health, Antananarivo, Madagascar.

29. (2000) Royal College of Obstetricians and Gynecologists Session: The humanizes care. Olath and Liverpool Tropical Medicine, Liverpool, UK.

30. Ravaoarisoa, Matangtoy, Rakotonirina (2011) Determinants of early neonatal mortality in maternity Bafelatanana, Antananarivo. African Journal of Anesthésie-Resuscitation and Emergency Medicine 30.

31. WHO, UNESCO, UNICEF (1997) Facts for Life. WHO Secretariat, Geneva, Switzerland.

32. Papiernik E, Pons JC, Goffinet F (2003) Prevention of prematurity. Flammarion medical science, Paris, France.

33. Cisse CT Martin SL, Ngoma SJ (1996) Early neonatal mortality at the maternity of the CHU of Dakar: current status and development trends between May 1987 and 1994. Journal of Medicine in Black Africa 30.

34. Cissé CT, Yacoubou Y (2006) Changes in early neonatal mortality between 1994 and 2003 at the University Hospital in Dakar. National School of Public Health, Dakar, Senegal.

35.SEED (2013) Knowledge Attitude and Practice Survey Mbujimayi. Kinshasa: Secretariat of the Ministry of Planning, DRC

36. Lawn JE, Cousens SN Zupan, RL (2013) Lancet Neonatal Survival steering team +4000000 Deaths When, Were, why?

37. Nagalo K, Dao F (2013) Morbidity and mortality of newborns hospitalized on 10 years at the El Fateh Suka Clinic, Ouagadougou. of final dissertation. University of Ouagadougou, Ouagadougou, Burkina Faso.

38. Yenan JP (2014) Neonatal morbidity and mortality in the pediatric ward of the University Hospital of Bouake (Ivory Coast). African Journal of Anesthésie- Resuscitation and Emergency Medicine 30.

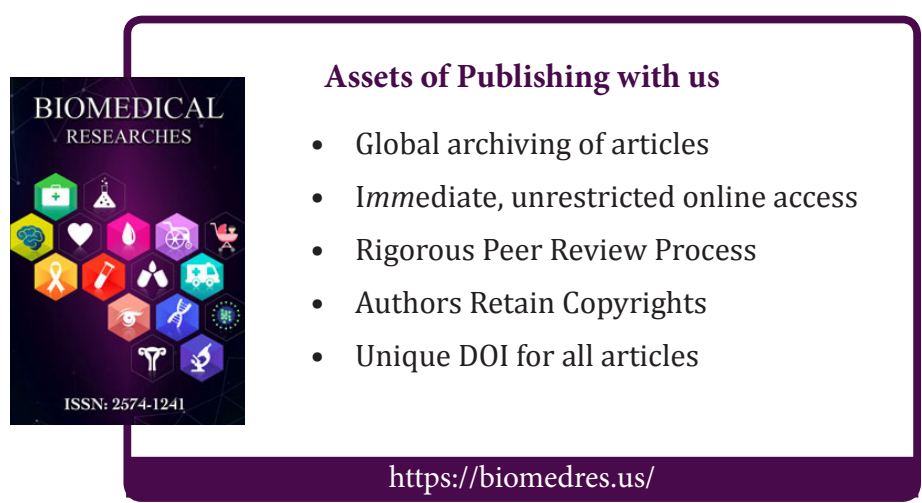

